\title{
British Women Travellers in Algeria, Tunisia, and Morocco, 1850-1930
}

\author{
By Amina Marzouk Chouchene*
}

\begin{abstract}
Algeria, Tunisia, and Morocco attracted many British women travellers mainly during the second half of the nineteenth century and the early decades of the twentieth. Although their number was smaller than that of their male colleagues, these women were attracted to the so-called North African Barbary States and left interesting accounts of their journeys. They recorded their perceptions of the various regions they visited and the people they encountered. Through examining a corpus of travelogues, this article explores these women's reasons for travelling to and writing about the three North African countries and their responses to the new lands. The article reveals that these women travellers enjoyed the climates, mineral springs, and natural landscapes of these countries.
\end{abstract}

Keywords: Algeria, Tunisia, Morocco, British women travellers, tourism

\section{Introduction}

In the second half of the nineteenth century, the presence of British women travellers in Algeria, Tunisia, and Morocco became much more remarkable. This is evident through the proliferation of women's travelogues describing their journeys to the so-called Barbary States of North Africa. This trend contrasts with the eighteenth century during which most travellers were males. British women's travels in the three North African countries were enabled, to a large extent, by the political stability following the French Revolution and the Napoleonic wars in the late eighteenth and early nineteenth centuries and the improved transportation.

The introduction of new means of transport such as steamships and railways facilitated the movement of women travellers to different parts of the world including Algeria, Tunisia, and Morocco. Although the number of British women travellers was smaller than that of men, their travelogues offer detailed descriptions of these North African countries. They provide interesting information about the climate, natural scenery, people's manners and customs, religion, and other interesting subjects. Nevertheless, scholarly attention to these women's travelogues remains scant. Most of the existing literature is particularly concerned with notorious male travellers such as John Drummond Hay, Arthur Leared, Thomas Shaw, Greville Temple, and others and considered these travellers' attitudes to the countries they visited and their obvious feelings of cultural superiority (Chamekh 2018, Manai 2007, Graves 2011).

Much of the rare literature on British women travellers in Algeria, Tunisia, and Morocco did not deviate from this perspective. In his article "Ellen M.Rogers

\footnotetext{
${ }^{*}$ Teaching Assistant, The Higher Institute of Theology-Tunis, Tunisia.
} 
as a Feminist and Orientalist Travel Writer," Mouloud Siber provided an analysis of the Orientalist and feminist discourses in Ellen Rogers's A Winter in Algeria. As a travelogue that confirms the West's Orientalist attitudes to Algeria, $A$ Winter with Algeria is, according to Siber, laden with negative representations of Algerian people. Rogers described them as politically, culturally, and intellectually inferior to the French and Europeans and especially the English. They were lazy. Unsurprisingly, the average Englishmen engaged in Algiers "take infinite pains in training the ouvriers under them, but the Arabs are usually so lazy that they have to be trained with an iron fist" (Rogers 1865: 53). Moreover, Arabs were regarded by Rogers as habitual liars. This makes French colonization of Algeria a legitimate act. The travelogue, according to Siber, shows also Rogers's feminist stance. The status of Algerian women as "subjects in need of salvation by their British feminist sisters" is a ubiquitous theme in her travelogue (Siber 2016: 1). The author concluded that the desire to emancipate Algerian women is clearly expressed by Ellen M. Rogers.

British women travellers' perceptions of local women surface also in Adel Manai's British travellers in Tunisia. Most of the travelogues analyzed by Manai were written by male travellers given the fact that British travellers who journeyed in Tunisia during the nineteenth and early twentieth century were mostly males. Yet British women travellers' views of Tunisian society and culture are particularly highlighted in Manai's chapter on "Women and the Harem."

Being an exclusive space, British women travellers such as Norma Lorimer, Nesbitt France, Lady Herbert, and others "had the privilege to visit Tunisian harems and report on everything they saw and experienced" (Manai 2007: 65). In other terms, they "were direct eyewitnesses" (Manai 2007: 65). They described Tunisian women's physical appearances, their dresses, their makeup, and their social ceremonies. In most of their descriptions, their feelings of cultural superiority are obvious. Francis Nesbitt attended a wedding ceremony and described the women as "short and generally stout, handsome in a rather heavy way, with thick painted eyebrows, darkened eyelashes, and henna stained hands" (Manai 2007: 70). She concluded that "all the married women however young, were moving mountains of fat" (Manai 2007: 70). Based on these descriptions and others, Manai rightly remarked that women's subsidiary position was a major theme in British women's travelogues. He concluded that "travellers' descriptions and views of women, with a few exceptions, properly fit in the much broader framework of Western perceptions of what is generally referred to as the Oriental woman" (Manai 2007: 65).

Amy J. Johnson also analyzed the writings of a number of late nineteenth and early twentieth century Western women in Morocco including those by some British women such as Amelia Perrier, Eleanor Elsner, and Mrs Howard Vysse. Johnson is mainly interested in highlighting how these women perceived Moroccan women and their role within society and determining the validity of Melman's major argument that Western women perceived the Orient in a different way from male travellers. Through the major themes of marriage and divorce, life in the harem, women's dress and appearance, the economic function of women and women and religion, the author classified women travellers into three 
categories: those who were extremely or mildly critical of the position of Moroccan women, and those who accepted the role of women in Moroccan society. In this way, Johnson did not deal with Western women travellers as a homogenous group. Nevertheless, she noted that gender relations were at the heart of their writings and that this often led, as in Perrier's case, "to greater reflection on the role and status of women within their own society" (Johnson 2001: 230).

This article seeks to contribute to the existing literature on British women travellers in Algeria, Tunisia, and Morocco by considering their motivations for travelling to and writing about the North African Barbary States and their representations of the new lands. It spans the second half of the nineteenth century and the early years of the twentieth which coincided with the rise of tourism. The advent of new means of transport such as railway travel, and steamships provided cheaper and safer means of travel over long distances. Women took advantage of these changes and there was a consequent rise in the number of women traveling around the world. The period witnessed also what is commonly referred to as the democratization of travel. Thomas Cook's tours made travel for leisure and recreation easier and cheaper. Jennifer Speake affirmed that "by providing escorted and lower-cost journeys, and taking care of all the mundane and intimidating details of travel (choosing an itinerary, buying the proper tickets, finding a decent hotel, exchanging currency), Cook made large strides towards the democratization of travel" (Speake 2003: 279). As a result, women began to travel to the Barbary States of North Africa that were traditionally visited by male aristocrats.

The article aims to answer the following major questions: Why were these women attracted to these North African countries? How did they react to the new lands they visited? The next section presents some of the primary and secondary sources I relied on to address these questions. The following two sections clearly examine these women's reasons for visiting and writing about Algeria, Tunisia, and Morocco and their responses to the new lands.

\section{Research Method}

The research method is both analytical and descriptive. It pays close attention to British women travellers' motivations for travelling to and writing about Algeria, Tunisia, and Morocco. At the same time, it considers how these women perceived the three North African lands. The article is also based on a number of travelogues by British women who journeyed in these countries in the second half of the nineteenth and the early decades of the twentieth century as a primary source. These include but not limited to Herbert's A Search After Sunshine or Algeria in 1871, Betham-Edwards's A Winter in the Swallows, Amelia Perrier's A Winter in Morocco, Eleanor Elsner's The Magic of Morocco, Mrs Greville Nugent's A Land of Mosques and Marabouts, Emily Ward's Three Travellers in North Africa, Lady Warren's Through Tunisia and Algeria on a Motorcycle. Little biographical information exists about most of these women. Nevertheless, their travelogues illuminate our understanding of their representations of the three North African countries under discussion. Unlike other sources, these women's 
travelogues cover almost every aspect of the countries they visited. The weather conditions, political systems, trade and commerce, people's manners, religious beliefs and practices, were some of the predominant themes in these women's writings.

This article relies also on secondary literature on travel and tourism such as the works of Kenneth J. Perkins, Adel Manai, and Vladimir Jankovic. These sources offer interesting analyses of British travellers' perceptions of Algeria, Tunisia, and Morocco and the rise of health tourism.

\section{Reasons for Visiting and Writing about Algeria, Tunisia, and Morocco}

Some of the British women travellers under discussion wrote about their reasons for traveling to the Barbary States of North Africa. Some of them visited Algeria, Tunisia, and Morocco in search for health. These women fall into two main groups: those who were suffering from "a clear physiological disease" (Morris 2018: 2) such as the baroness Mary Elizabeth Herbert and Isabella Bird. Herbert declared that her journey to Tunisia and Algeria was spurred by a desire "to test the efficacy of certain warm springs, which had been strongly recommended to [her] by a Paris doctor for rheumatism" (Herbert 1872: 3). Isabella Bird journeyed in Morocco and other parts of the world in 1901 following her doctors' orders who recommended her these regions in order to be relieved from her back pains and insomnia. The doctor advised that a "sea voyage and a change of air would restore her health" (Chaouch 2004). Other women such as Ellen Rogers fall within the second category, those who thought that a change of air would keep them healthy. Rogers visited Algeria in October 1863 based on the widespread belief that a change of air would be beneficial to her health. Although she had very little information about the country, she was influenced by the opinion of a German writer that "excursions to new regions are useful, to rub off the cryptogamic growths with which too long a residence in one of the same country, is apt to encrust the human soul" (Rogers 1865: v-vi). These women's journeys to the three North African countries for therapeutic reasons are part of a well-established practice of British travel for health.

A number of nineteenth publications such as Thomas More Madden's On Change of Climate: A Guide for Travellers in Pursuit of Health and Isaac Burney Yeo's Climate and Health Resorts emphasized the intertwined relationship between climate and health. Physicians often recommended travel to foreign climates to patients suffering from physiological or nervous ailments. Lara Marks and Michael Worboys rightly pointed out that:

the notion that the body was influenced by its environment was commonplace in medicine and wider Western culture in the eighteenth and nineteenth centuries. It followed that a change of air or travel to a different area were ways to improve health, and doctors tried to match a person's constitution and illness with potential healing environments (Marks and Worboys 1997: 8). 
The Mediterranean was a popular destination for many Victorians seeking health and repose. John Pemble affirmed that climate therapy played a central role in fuelling the "Mediterranean passion."Victorian climate therapists discussed the effects of different climates on people's minds and bodies. They stressed the importance of choosing the right climate for every ailment. Sedative climates were particularly recommended in cases of inflammatory and feverish affections marked by an irritable or hysterical disposition and gastric and nervous dyspepsia. On the other hand, diseases of debility indicated by a low pulse, a gloomy or lymphatic temperament, a tonic or sluggish dyspepsia need a tonic climate (Pemble 1987: 92). British winters were seen by the Edinburgh professor, James Gregory, as an "exciting cause of chronic disease for which the physicians had no remedy but to wait for summer, or what seemed equally logical, travel to summer" (Jankovic 2006: 274). Gregory explained that the British weather with its extremes of hot and cold had a negative effect on people's health. On the contrary, the dry and warm climate of Mediterranean winters was highly recommended.

This was confirmed by many statistics about the temperature, rainfall, hours of sunshine, direction and velocity of winds, atmospheric pressure, humidity, electricity, and other factors. Thermometers, barometers, pluviometers, and military statistics confirmed also the beneficial impact of the Mediterranean (Pemble 1987: 92). Based on the army reports of the 1830s, Dr Johnson Davy, Inspector General of Army Hospitals, concluded that the warm and dry climate of the Mediterranean "counteracted the effects of poor accommodation and dissipation, and so kept down both mortality from consumption among native populations" (Pemble 1987: 92). Based on this therapeutic value of the Mediterranean, some of the British women travellers under discussion visited Algeria, Tunisia, and Morocco "in quest of physical health, mental diversion, and rejuvenation of sprits and stamina" (Jankovic 2006: 271).

Other British women travelled looking for novel places and experiences. Lady Warren journeyed in Tunisia in 1922 in company of her husband in search for risk, adventure, and the "super oriental" (Warren 1922: 11). Eleanor Elsner visited Morocco out of a romantic desire to see "lands where these the sun shines and the sky is blue, places where the quietness and dignity of the old life still counts for something" (Elsner 1928: 14). Similarly Mrs Greville constructed Tunisia and Algeria in a romantic way. In these countries, the traveler could still enjoy the beauty and authenticity of times past. Greville wrote that:

I can, if you will take my hand, lead you through these cities where the women walk veiled and trousered, where a strange monotonous music strikes the ear and when a wealth of wondrously harmonized color delights the eye. Pluck a few flowers with me from the soil of this marvelous Africa, that so, amid the mirk of dire December days in England, you may yet know that beauty and la joie de vivre are not wholly things of the past (Greville 1894: 2).

While some of these women did not express clearly their reasons for traveling, they stated their purposes in writing their travelogues. Lisbeth Gooch Strahan clearly admitted that she wanted her travelogue to be a guidebook for visitors to Algeria. She noted the scarcity of books written on Algeria in English and 
intended her travelogue to fill in this gap (Strahan 1878: preface). Unsurprisingly, Strahan offered advice for future travellers about their daily necessities. They should bring with them proper clothing including an umbrella and smoked glasses which would protect them from the "burning sun." Moreover, they need to follow a healthy diet (Strahan 1878: 12). Likewise, Mrs Howard- Vyse suggested that the major purpose of her travelogue $A$ Winter in Tangier was to provide information about Tangier, "the surrounding country and its climate as little is known of these" (Howard-Vyse 1882: 11) especially for those seeking a wild winter climate. Emily Ward purported her travelogue Three Travellers in North Africa, to be "of use to future travellers....and help them in making their own itinerary" (Ward 1920: vi). Similarly, Amelia Perrier avowed that her purpose in writing A Winter in Morocco was to provide information about a country that was unknown to many Britons. She wrote:

I know nothing about the country when I went there. Everything I saw was novel and interesting to me. And it is for that section of the reading public whose minds may be in the same blank condition on the subject that mine was, that I have written down my experiences in Morocco, and described, as well as I could, all that I saw and heard there, in the hope that even thus at second hand, it may afford some amusement, and perhaps a little instruction, to them also, as it did to me (Perrier 1873: vi).

Certainly by providing the information needed for prospective travellers, these women's travelogues functioned as a guidebook for those who wanted to know more about foreign places and people, who were afraid of being lost, and those who needed to be reassured about their personal safety and health in a foreign climate. This was a major concern for British women travellers in Algeria, Tunisia, and Morocco and the climatic conditions are a common theme in these women's travelogues.

\section{British Women Travellers' Responses to the New Lands}

The British women travellers under discussion wrote positively about the climates of the Maghrebean countries they visited. Their travelogues abound with constant references to the weather conditions and most importantly the therapeutic value of the climates of these countries. Strahan praised the moderate nature of Algeria's climate. She quoted the opinions of many eminent doctors on the subject such as Dr. A. Mitchell of Edinburgh who wrote and published newspapers on Algeria's climate in the British and Foreign Medico-chirurgical Review, Dr. Shaw who was chaplain to the English factory in Algiers from 1720-1730, and extracts from the work of the British physician and anthropologist Dr. Eugene Bodichon. Dr. Mitchell found that the "the weather is delightful, being neither too hot nor too cold" (Strahan 1878: 5). Additionally, he suggested that the evenness of the temperature mainly from October to the end of May made Algeria's climate charming (Strahan 1878: 5). 
Similarly to Dr. Mitchell, Dr Shaw stressed the evenness of the Algerian climate. Dr. Bodichon, on the other hand, offered a list of the people to whom the climate may be beneficial and to those it might be harmful. Persons of dry temperament, elderly people, rheumatic subjects, people of lymphatic temperament, and those predisposed to phthisis would regain their health. Yet the climate may not be beneficial to fat people, those suffering from a hypertrophy of the heart of large vessels, dysentery, organic diseases, nervous exhaustion, and drunkards. After citing the opinions of these doctors, Strathan came to the conclusion that "there can be no doubt that the first, the chief, the ever present charm of Algiers is its beautiful climate" (Strahan 1878: 11). Ellen Rogers stressed as well the beneficial impact of the Algerian climate on the health of invalids, mainly for those in an early stage of lung disease (Rogers 1865: 101). Matilda Betham Edwards found the Algerian climate genial especially from October to May (Betham Edwards 1867: 247). She affirmed that it is particularly beneficial to elderly people and to invalids suffering from phthisis, rheumatism, scrofula, gout and lymphatic temperaments (Betham Edwards 1867:249).

These favorable comments on the Algerian climate explain the fact that Algeria was a popular winter resort for many Britons' in the nineteenth and twentieth century. Kenneth Perkins suggested that starting from 1837, many British physicians took special interest in highlighting the medical and curative qualities of the Algerian climate which made the country a perfect winter venue (Perkins 2013: 217). Adel Manai reiterated a similar argument and emphasized that from the 1830s onward until the outbreak of WWI, Algeria was "one of the most appreciated winter resorts in the world rivaling the French Riveira, Southern Spain, Madeira, Switzerland" and other popular winter resorts (Manai 2018a: 2). He persuasively remarked that Algiers (the capital) was seen as a perfect winter resort "to such an extent that in 1937, the French Larousse dictionary defined the term "hiverneurs" (meaning winter residents and tourists) as those who spend the winter in Midi, Algiers" (Manai 2018a: 2). Certainly, British women travellers' glowing descriptions of the Algerian climate referred to earlier contributed to establishing the reputation of the country as an excellent winter venue. British women, who visited Morocco in the second half of the nineteenth century and the early twentieth, praised as well the curing qualities of the climate.

Eleanor Elsner, who journeyed in Morocco in company of several other men and women, wrote that, "after I had been in the town for some time I came to the conclusion that I should love to live there, because the climate is incomparable, and it is impossible to be bored" (Elsner 1928: 232). Amelia Perrier praised the local climate and quoted Arthur Leared's view that it was "delightful, bright, and bracing with no extremes of cold or heat" (Perrier 1873: 353). Similarly to Algiers, Tangier started to be reputed as a winter health resort from the mid-nineteenth century.

This reputation reached its climax in 1873 with the publication of Arthur Leared's article entitled "Tangier as a winter resort for Invalids" (Martinez 2017: 58). The article was published "in the prestigious British medical journal The Lancet" (Martinez 2017: 58). The Irish doctor, who was a medical graduate of Dublin's Trinity College and Fellow of the Royal College of Physicians of 
London, wrote favorably about Tangier (Martinez 2017:58). He visited the country twice in the 1870s and wrote two travel accounts about his journey: his book Morocco and the Moors (1876) and A Visit to the Court of Morocco (1879). He affirmed that Tangier was "well suited for an invalid residence," mainly "for consumptive tuberculosis patients" (Martinez 2017:59). He highlighted its equable climate and its even temperature with no extremes of heat and cold in winter and summer. For Leared such a climate makes Tangier "a healthy town" despite the fact that the "sanitary arrangements are very imperfect" (Martinez 2017:59). Unsurprisingly, Leared considered Tangier's climate as much more favorable to that of Madeira, Egypt and even Algiers, which were the three most visited countries by British invalids (Martinez 2017:59).

Although references to the climate and discussions of its curing qualities are scant in British women travelogues about Tunisia, Mary Elizabeth Herbert noted, on her way to Tunis, that she was accompanied by an Irish family who wanted their elderly son to reap the benefits of a healthy climate (Herbert 1872: 243). Adel Manai interestingly noted that by the late nineteenth century there was a common belief that Tunisia would be "a popular winter health resort" (Manai 2018b: 52).

This is evident in the comments of some of the British women travellers who visited Tunisia in the late nineteenth and early twentieth century. They admired the sea and health resorts which the local population benefited from and which some of them found much pleasurable and beneficial. Emily Ward admired the spa town of Korbous and described it as a "wonderfully beautiful spot, where rheumatic, lane and very fat people seek a cure" (Ward 1920: 147). There, she saw very fat jewesses who came to benefit from the curing qualities of water. The height of the spot and the hills protect the invalids from the wind and healing waters sprang out of the mountain-side (Ward 1920: 147).

It is interesting to note that Korbous was not only a popular among Tunisians. Eric Jennings demonstrated that the sea and health resort was a favorite hydromineral spa for the local population, and French colonials with its healthy temperate marine climate and hydro mineral waters during the nineteenth century (Jennings 2006: 154). Julia Clancy Smith showed that resident and European visitors used the waters of Korbous to treat rheumatism and other diseases such as arthritis, dermatis, and digestive problems (Clancy Smith 2011: 165). For example, the English consul general in Tunis, Sir Richard Wood visited the "Baths of Korbous" in November 1858 in order to cure his rheumatisms (Clancy Smith 2011: 165). This "health-seeking behavior" as Julia Clancy Smith calls it, is also clear through Erskine Stewart's delight in having a bath in al Hamma, an oasis with some thousands of date palms in Southern Tunisia. The spot was characterized by many Roman baths "made of slate, or some dark, coal substance" (Erskine 1925: 213). She was delighted with the hot water which "bubbled in at one end and went out at the other, making a delicious bath with the water changing all the time" (Erskine 1925: 213). Although tourism infrastructure was not developed enough in the early decades of the twentieth century, Erskine Stewart greatly appreciated the rest-house at al Hamma. The latter was quite comfortable with its big and white-washed sitting room. It had quite decent bedrooms with blue tiles 
on the walls, and a raised garden in the middle with a well in the centre (Erskine 1925: 213). Similarly, Herbert recommended to prospective travellers a tourist spot between Carthage and Goletta

where a number of villas and country houses or rather sea-side watering places of the Bey's family or his ministers; and I can conceive no more enjoyable spot in the summer-time than this sea shore with its big shady rocks, beautiful sands, lovely shells and glorious blue sky...Mrs Wood told me that it was her children's greatest delight to come here for the day for their country home at Marsa which is only a few miles off and did not wonder at their taste. Remounting the hill we came to the ruins of the famous temple of Esculapius. The view from thence and of the whole line of coast, with the range of mountains beyond, and the sparkling Mediterranean, was wonderfully beautiful (Herbert 1872: 285-259).

Certainly, these tourist spots provided entertainment to women travellers. Some of them sought pleasure and relaxation in the hot and mineral springs. British women travellers in Algeria such as Lisbeth Gooch Séguin Strahan enjoyed the hot springs of Hammam Rira, which was a major tourist attraction. Guidebooks such as Robert Lambert Playfair's and John Murray's Handbooks for Travelers in Algeria emphasized the therapeutic value of these mineral waters. Although Strahan noted that the Hammam is the site of the "most important of the many natural springs of Algeria," she did not deny the fact that the country abounds with mineral springs "of various temperatures" (Strahan 1878: 462). She offered a detailed description of the mineral springs of Hammam Rira and their various therapeutic uses. Some were saline and extremely beneficial in cases of rheumatism and cutaneous diseases (Strahan 1878: 463). Some others were ferruginous and "have marvelous effect" upon bodies weakened by fever, diarrhea, dysentery, and other diseases (Strahan 1878:463).

Moreover, Strahan admired the pure and sweet quality of the air of Hammam Rira. She wrote that "the air ...is pure and sweet, the temperature equal and even in summer, it is said that the sea-breezes, carried over the plain bring morning and evening a certain freshness which tempers the heat" (Strahan 1878: 464-465). Perrier offered also a detailed description of the hot springs of Hammam Rira, its location, the purity of the air and offered a detailed analysis of the ingredients of these waters and their curative qualities. Undoubtedly, Algeria is rich in mineral springs.

Herbert praised the curing qualities of the mineral springs of Biskra. She enjoyed them and was relieved from her rheumatism immediately. She wrote: "As I was suffering from numbness of one leg in consequence of the rheumatic fever I had had the previous winter, I resolved to try these waters, and was sensibly relieved by them even after first experiment" (Herbert 1872: 202). Although the spot lacked proper infrastructure and invalids were expected to bring all what they need from Biskra, Herbert had "very great faith, not only in the efficacy of the spring itself, but in the effect of warm dry climate of this place for all such ailings" (Herbert 1872: 202). Similarly, Mrs. Llyod Evans, who visited Algeria in 1867, described the mineral waters of Hammam Rira as "of great efficacy" (Evans 1868: 90). Moreover, she admired the "charming situation" of Hammam Meskoutin 
(Evans 1868: 322). The spot was surrounded by beautiful scenery. She was fascinated by the "grassy slopes," the "magnificent olives," and the "brilliant flowers," the verdure of the landscape and the unexpected discovery of hot springs (Evans 1868: 322). Certainly this description draws our attention to British women travellers' appreciation of the wild landscapes they found in Algeria, Tunisia, and Morocco. Most of their descriptions of the natural landscapes reflect the influence of the romantic movement of the eighteenth and nineteenth centuries. The movement venerated "nature as a benign, maternal goddess capable of renewing the spiritual batteries of jaded urbanites" (Beeton 2005: 5).

Ellen M. Rogers, who was very often annoyed by the "passing to and fro of dirty Arabs under the narrow arcades" of Algiers, was relieved by the pleasant atmosphere in the hills. She was particularly captivated by the summer residence of the Italian consul at el Biar. From there,

no words can paint the beauty of the distant coloring of the hills: the Plain of the Metidja, Cape Matifon, bathed in the warm glow of the setting sun, jutting out into the sea, with the deep blue waters forming a frame on three sides: snow wreaths and mists on some of the peaks of the Atlas, with others of the same range dipped in sunbeams, all seemed like enchantment (Rogers 1865: 87).

Matilda Betham-Edwards showed also great interest in Algeria's natural beauty. In a party of twenty, she reveled in a picnic and enjoyed drinking tea and eating cakes and strawberries under the shadow of olive trees (Bentham Edwards 1867: 171). Edwards was fascinated by the wild flowers of different types and colors: mignonette, rosemary, golden marigolds, and "beautiful tall asphodels, sprinkle the turf" (Bentham Edwards 1867: 21). In one of her walks, she enjoyed the breathtaking natural landscapes and wrote that:

the outlying country was lovely beyond description. We went out to pluck wild flowers, and in ten minutes our hands were full; there were crimson anemones, the pale asphodel, the iris, white and purple, marigolds large as roses, golden as ripe oranges, vetches purple, blue and pink, rosemary mignonette, and an infinity whose names I do not know. With this glory of color on the hills, a river rippling amid oleanders below, a fresh spring air quickening our pulses, and a horizon of mountains of every sides, here of the deepest green, there of dreamiest violet-who would not envy us such as walk (Bentham Edwards 1867: 122).

Likewise, British women travellers appreciated the natural beauty of Tunisia. Their travelogues abound with glowing descriptions of the natural scenery. On her way from Bizerta to Tunis, Mrs Greville asserted that the scenery was magnificent. She was delighted to see bold cliffs, with mountains in the background and at times a rocky islet upstanding in the blue sea (Greville 1894: 139). Francis Nesbitt was impressed with the "wondrous blue" of the Mediterranean and the lagoon of the Bahira. She was fascinated with the scene with its distinctive beauty as: 
the water shimmers in the sunshine and the town of La Goulette gleams likewise and so do the houses scattered along the coast. The slopes of the hill and the whole of the plain towards the sea are covered as it were with cloth scarlet and gold and green, poppies and marigolds and a waving corn, in masses such as can rarely be found elsewhere (Nesbitt 1906: 183).

She commented further on the fantastic scenery as the twin peaks of Bou Korneine, the Gemini Scopuli of Virgil were "soft as a dream in the early morning" (Nesbitt 1906: 183). Seen from a distance, the ancient ports of Carthage still keep their original form. The tiny lakes were "calm as glass and almost more definitely blue than the Mediterranean" (Nesbitt 1906: 183). She concluded that the view was beautiful on all sides. A similar attitude can be found in Eleanor Elsner's The Magic of Morocco, Howard Vyse's A Winter in Tangier, and Perrier's A winter in Morocco. These women, like British women travellers in Tunisia and Algeria, show a romantic appreciation of the wild scenery.

\section{Conclusion}

This paper has explored some of the travelogues written by British women who visited Algeria, Tunisia, and Morocco in the second half of the nineteenth century and the first half of the twentieth. Lady Herbert, Amelia Perrier, Emily Ward, Ellen Rogers, and others took advantage of the unprecedented travel opportunities offered by the development of new means of transport and journeyed in different parts of these Maghrebean countries. The paper has paid close attention to these women's reasons for travelling to and writing about the three countries. It has dwelt also on their representations of the new lands. It has revealed that these women enjoyed the climates, hot springs, and natural landscapes of the three North African countries. Most interestingly, these women's favorable descriptions suggest that Algeria, Tunisia, and Morocco were attractive tourist destinations for many British women travellers at least during the period under discussion. They also indicate the importance of what Vladimir Jankovic termed as "the health factor" (Jankovic 2006: 271) in motivating women's journeys to foreign lands. As I already pointed out, some women travellers such as Mary Elizabeth Herbert, Isabella Bird, and Ellen Rogers travelled for health reasons. Other women such as Emily Ward, Lisbeth Gooch Seguin Strahan, and Erskine Stewart admired and enjoyed the hot springs and praised their curing qualities. This is a compellingly interesting aspect of these women's views of the three North African lands that has received scant attention in the existing literature. It opens as well new avenues for further research, for example, on whether these women's favorable impressions of the climates of Algeria, Tunisia, and Morocco were shared by their male counterparts. 


\section{References}

Beeton S (2005) Film-induced tourism. Toronto: Channel View Publications.

Betham-Edwards M (1867) A winter with the swallows. London: Hurst and Blackett.

Chamekh M (2018) Algeria in British travel writing (1850-1930): images and perceptions. Athens Journal of Tourism 5(4): 271-282.

Chaouch K (2004) British travellers to Morocco and their accounts, from mid- $16^{\text {th }}$ o mid$20^{\text {th }}$ centuries: a bibliography. Working Papers on the Web. Representing Morocco 7.

Clancy-Smith J (2011) Mediterraneans: North Africa and Europe in an age of migration c.1800-1900. Berkeley: University of California Press.

Elsner E (1928) The magic of Morocco. New York: Dodd, Mead.

Erskine S (1925) Vanished cities of Northern Africa. London: Hutchinson. Evans HL (1868) Last winter in Algeria. London: Chapman and Hall.

Graves MS (2011). A certain barbaric originality: Moroccan pottery as viewed by British travel writers of the nineteenth century. The Journal of North African Studies 12(4): 501-516.

Greville NE (1894) A land of mosques and marabouts. London: Chapman \& Hall Ld.

Herbert ME (1872) A search after sunshine or Algeria in 1871. London: Richard Bentley $\&$ Sons.

Howard-Vyse L (1882) A winter in Tangier and home through Spain. London: Hatchards.

Jankovic V (2006) The last resort: a British perspective on the medical South, 1815-1870. Journal of Intercultural Studies 27(3): 271-298.

Jennings E T (2006) Curing the colonizers: hydrotherapy, climatology, and French colonial spas. Durham, N.C: Duke University Press.

Johnson A (2001) Orientalism and gender: the condition and status of women in Morocco. In P Starkey, J Starkey (eds), 209-233. Interpreting the orient: travellers in Egypt and the near East. Reading, Great Britain: IthacaPress.

Manai A (2018a) Early Algerian tourism. https://www.researchgate.net/publication/32766 4756_Early_Algerian_Tourism.

Manai (2018b) The origins of Tunisian tourism. Journal of Mediterranean Studies 27(1): $49-61$.

Manai (2007) British travellers in Tunisia, 1800-1930: a history of encounters and representations. Tunis: Centre for University Press.

Marks L, Worboys M (1997) Migrants, minorities, and health: historical and contemporary studies. London and New York: Routledge.

Martinez FJ (2017) Mad at Tangier: hygienist discourses, mental disorders, and european competition for hegemony in early twentieth century Morocco. The Journal of the Middle East and Africa 8(1): 57-73.

Morris RE (2018) The Victorian 'change of air' as a medical and social construction. Journal of Tourism History 10(1): 49-65.

Nesbitt F (1906) Algeria and Tunis painted and described. London: A \& C Black.

Pemble J (1987) The Mediterranean passion: Victorians and Edwardians in the South. Oxford: Oxford UP.

Perkins KJ (2013) So near and yet so far: British tourism in Algiers, 1860-1914. In M Farr, X Guégan (eds), 217-235. The British abroad since the eighteenth century, Volume 1. London: Palgrave Macmillan.

Perrier A (1873) A winter in Morocco. London: H.S. King.

Rogers EM (1865) A winter in Algeria, 1863-64. London: Sampson Low, Son and Marston.

Siber M (2016) Ellen M. Rogers as a feminist and orientalist travel writer: a study of her $a$ 
winter in Algeria: 1863-64. Alicante Journal of English Studies 29(Dec): 213-228. Speake J (2003) Literature of travel and exploration. New York: Fitzroy Dearborn.

Strahan L (1878) Walks in Algiers and its surroundings. London: Daldy and Isbister and Co.

Ward E (1920) Three travellers in North Africa. London: John Lane.

Warren L (1922) Through Algeria and Tunisia on a motor bicycle. London: Jonathan Cape. 
